\title{
Zirconia Surface Treatment by Different Output Powers of Er: YAG Laser and Sandblasting: SEM Evaluation
}

\author{
Mohammad Hashem Hosseini, ${ }^{1}$ Ardavan Etemadi, ${ }^{2}$ and Fatemeh Gorjizadeh ${ }^{3,{ }^{*}}$ \\ ${ }^{1}$ Assistant Professor of Orthodontics, Dental Research Center, Tehran University of Medical Sciences, Tehran, Iran \\ ${ }^{2}$ Assistant Professor of Periodontics, Laser Research Center of Dentistry, Dental Research Institute, Tehran University of Medical Sciences, Tehran, Iran \\ ${ }^{3}$ Postgraduate Student of Orthodontics, Department of Orthodontics, School of Dentistry, Tehran University of Medical Sciences, Tehran, Iran \\ "Corresponding author Fatemeh Gorjizadeh, Department of Orthodontics, School of Dentistry, Tehran University of Medical Sciences, Tehran, Iran. E-mail: \\ fatemegorjizade@gmail.com
}

Received 2016 May 28; Accepted 2016 September 22.

\begin{abstract}
Background: Application of zirconia in dentistry has increased due to its good properties. Since zirconia is not possible to be etched, evaluation of the other methods of surface treatment is important.

Objectives: The aim of this study was to evaluate zirconia surfaces treated by different output powers of Er: YAG laser and sandblasting technique by scanning electron microscope (SEM).

Materials and Methods: 15 specimens were prepared of 3Y-TZP ceramic material. After polishing of all the samples, divided into 5 groups; control group, 1.5 W Er: YAG laser irradiated group, 2.5W Er: YAG laser irradiated group, 3.5 W Er: YAG laser irradiated and sandblasted group. Then SEM image of each group were prepared and analyzed.

Results: The SEM images of study groups showed there is no significant difference between control group and laser groups at $\times$ 3000 , but at the more magnifications $(\times 15000$ and $\times 60000)$, with increasing laser power, surface roughness and deformation of crystals increases. SEM of Sandblasted group showed a change in surface texture with the formation of microretentive grooves and deformation of zirconia crystals shape.

Conclusions: By increasing the Er: YAG laser power on zirconia ceramics, the surface roughness increases but not impressive. Application of sandblasting technique on zirconia provides greater surface roughness than Er: YAG laser treatment. 1.5 W (150 mJ) Er: YAG laser radiation has no significant effect on surface morphology of zirconia but $2.5 \mathrm{~W}(250 \mathrm{~mJ})$ and $3.5 \mathrm{~W}$ ( $350 \mathrm{~mJ})$ outputs, change the surface morphology.
\end{abstract}

Keywords: Zirconia, Er: YAG Laser, Morphology

\section{Background}

Zirconia is a type of ceramic that has recently attracted dentists and patients because of its desirable features (1). Zirconia has excellent biocompatibility (2), its color is similar to tooth and its mechanical properties is similar to stainless steel (3). It has three temperature-dependent pattern: 1. monoclinic 2. tetragonal 3. cubic. The tetragonal pattern that comes after the $1170 \mathrm{C}^{\circ}$ heat treatment is the most useful form of zirconia in dentistry. Metal oxides such as $\mathrm{MgO}, \mathrm{CaO}$ or $\mathrm{Y}_{2} \mathrm{O}_{3}$ is added to it for stability at room temperature. At present, tetragonal polycrystalline zirconia stabilized with Yttrium (Y-TZP) is the best-known and most widely used combination of zirconia in dentistry (2, 4). When stress leads to a crack on the surface of a zirconia, crack energy makes a phase change, tetragonal to monoclinic, since monoclinic crystals are bigger in size than tetragonal a volume increase happens at the region which leads to crack seal (2) and high hardness of zirconia (4). This feature of zirconia that improves its physical and mechanical properties is named "Transformation Tough- ening" (5).

To increasing bond strength of orthodontic attachments to dental restorations, different methods of surface treatment have been used. Application of acid etching technique for surface treatment of porcelain causes a good bond strength for metal brackets $(6,7)$ but this method is not efficient on zirconia since it has no silica and glass phase (8). Finding new ways to improve bonding to zirconia is important.

Laser is used in dentistry for different purposes; for example, caries removal, cavity preparation and surface treatment of restorations $(8,9)$. The absorption of laser energy by the substrate is the most important interaction between the laser and the substrate $(10,11)$. Er: YAG laser radiation is significantly absorbed by water and hydroxyl group of apatite crystals in dental hard tissues. The laser heat increases the pressure and volume which creates microscopic damages that lead to the removal of dental hard tissues (12-14). Er: YAG laser has a wavelength of $2940 \mathrm{~nm}$ and a pulse mode of radiation. It can create clear and accurate edges in enamel. Its damaging effects on the pulp is 
not significant because the depth of its influence is negligible. Cavity preparation by Er: YAG compared with grinding, is less likely to cause adverse pulp reactions. When the laser is used to remove decay, it usually does not require local anesthesia. Application of erbium: yttrium-aluminumgarnet (Er: YAG) laser for surface treatment before bonding of brackets have shown acceptable results $(8,9)$.

Sandblasting with $\mathrm{Al}_{2} \mathrm{O}_{3}$ is another common technique, used for surface treatment. Using this technique on ceramics, removes the contaminated layer, increases the available bonding area and improves the wettability of luting materials (15).

\section{Objectives}

The aim of this study was to evaluate zirconia surfaces treated by different output powers of Er: YAG laser and sandblasting technique by scanning electron microscope (SEM).

\section{Materials and Methods}

15 ceramic specimen with dimension of $10 \mathrm{~mm} \times 10$ $\mathrm{mm} \times 7 \mathrm{~mm}$ were cut from presintered block of 3Y-TZP ceramic material (Dental Direct, Germany) using cutting machine (Mecatome T201A, France) under water cooling. During sintering process about $20 \%$ shrinkage occurred, finally the samples with a dimension of $7 \mathrm{~mm} \times 7 \mathrm{~mm} \times 5$ $\mathrm{mm}$ were obtained. The sintering process was conducted in accordance with the manufacturer's instructions. The ceramic surfaces were then polished in a polishing machine using a series of silicon carbide abrasive papers in sequence (grit 120, 220, 600, and 1,200; Struers, Ballerup, Denmark) for 15 seconds under water irrigation at 150 rotations per min to obtain flat surfaces. The specimens were then randomly divided into five groups.

Group 1, control: No surface conditioning procedure was applied to this group.

Group 2, laser treatment: In the second group, the surface of zirconia specimens were irradiated by Er: YAG laser (Smart 2940 D Plus, DEKA laser, Florence, Italy) with Output power and energy of $1.5 \mathrm{~W}$ and $150 \mathrm{~mJ}$, in long pulse mode, with a wavelength of $2940 \mathrm{~nm}$, frequency of $10 \mathrm{~Hz}$, for 20 second. The distance of laser application was $2 \mathrm{~mm}$ in all groups. At high powers of laser irradiation with increasing of the temperature, water irrigation was done automatically.

Group 3, laser treatment: In the third group the surface of zirconia samples were irradiated by Er: YAG laser, with Output power and energy of $2.5 \mathrm{~W}$ and $250 \mathrm{~mJ}$, long pulse mode, wavelength of $2940 \mathrm{~nm}$, frequency of $10 \mathrm{~Hz}$, for 20 second.
Group 4, laser treatment: In the fourth group, the surface of zirconia samples were irradiated by Er: YAG laser, with Output power and energy of $3.5 \mathrm{~W}$ and $350 \mathrm{~mJ}$, long pulse mode, wavelength of $2940 \mathrm{~nm}$, frequency of $10 \mathrm{~Hz}$, for 20 second.

Group 5, sandblasting: The zirconia surfaces were sandblasted with $50 \mu \mathrm{m} \mathrm{Al}_{2} \mathrm{O}_{3}$ particles from a distance of $10 \mathrm{~mm}$ and at a pressure of 20 psi for 5 seconds.

SEM analysis: Before the SEM analysis, the zirconia specimens were gold coated with a sputter coater (Desk sputter coater - DSR1, Iran). Finally, Images from each group were taken using electron microscope (Hitachi S4160, Japan).

\section{Results}

The SEM images of study groups (Figures 1, 2, 3 and 4) showed no significant difference between control group and laser groups at $\times 3000$, but at the more magnification $(\times 15000)$, by increasing laser powers, surface roughness and deformation of crystals increased. SEM of Sandblasted group (Figure 5) showed a change in surface texture with the formation of microretentive grooves and the deformation of crystals shape.

\section{Discussion}

The purpose of this study was to evaluate zirconia surfaces treated by different powers of Er: YAG laser compared to sandblasting technique in a qualitative manner. In the present study Sandblasting technique caused a rougher surface with irregularities rather than laser treatment. Subasi et al and Caglar et al. also demonstrated that the sandblasting method provided rougher surfaces than Er:YAG laser radiation and this method can be used to obtain micromechanical retention $(16,17)$. Whatever the size of $\mathrm{Al}_{2} \mathrm{O}_{3}$ particles and Sandblasting time increases the possibility of phase change and creation of surface roughness increases (18). In our study, the size of particles and duration of sandblasting were $50 \mu \mathrm{m}$ and 5 seconds which compared to studies of zirconia is very cautious; however, SEM images of sandblasted group show phase change to monoclinic has happened probably, because crystal shapes has changed, and surface roughness is evident; although determining the precise amount of phase change and the surface roughness requires XRD analysis and profilometer device, respectively. A study have shown that biaxial flexural strength of the Y-TZP materials significantly increases after sandblasting and sandblasting causes more amount of monoclinic phase rather than grinding (19).

Some studies have shown that smooth surfaces surrounded with microcracks are created after Er: YAG laser 

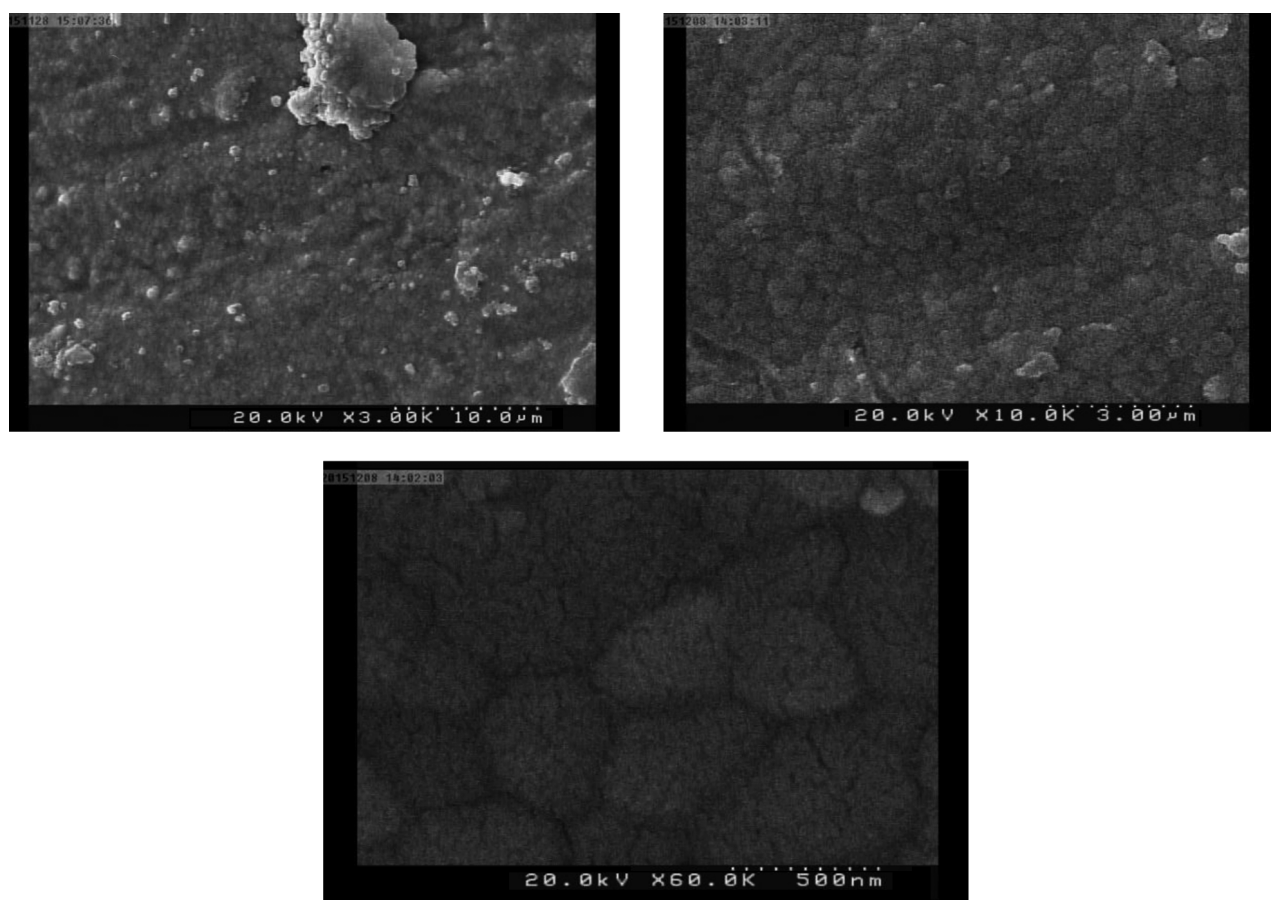

Figure 1. Zirconia Surface, Control Group (Original Magnification $\times 3000, \times 15000$, and $\times 60000$ )
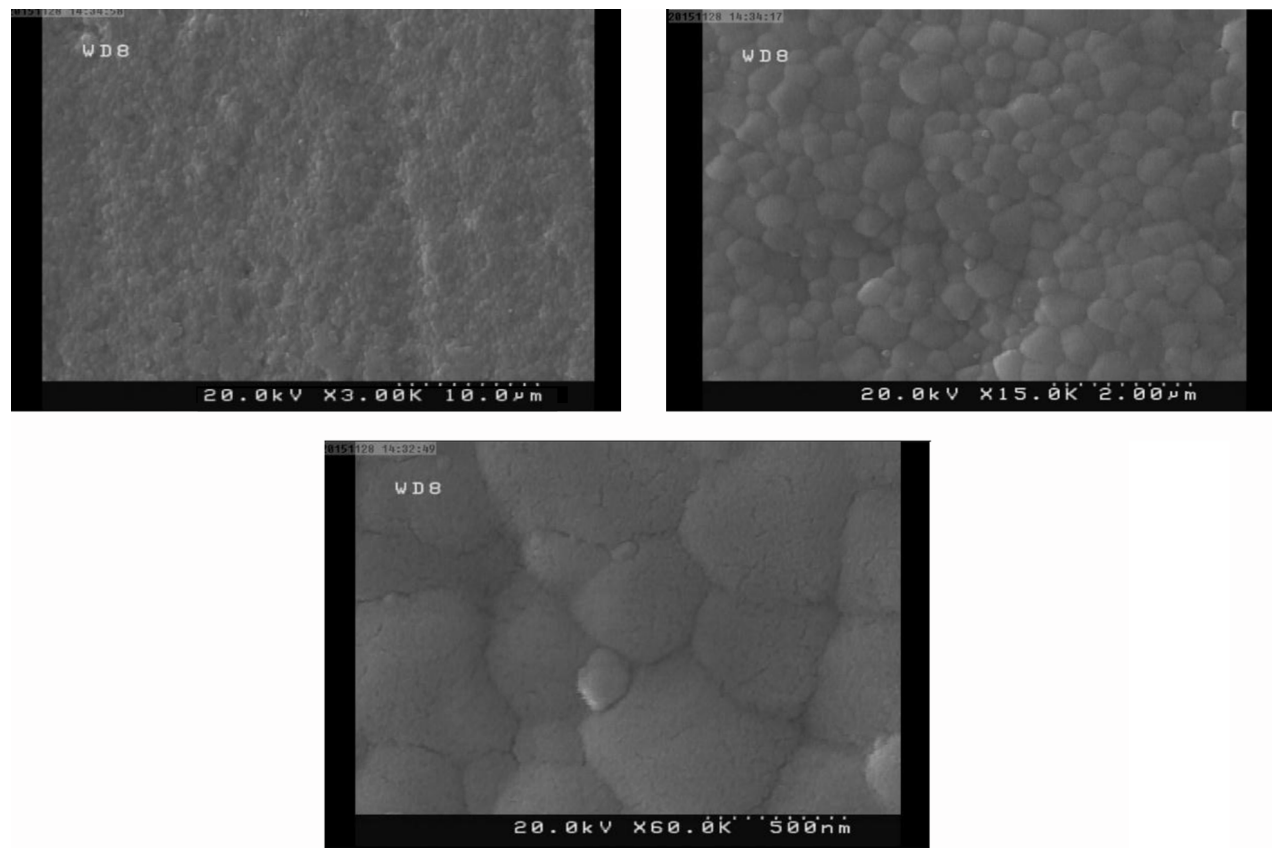

Figure 2. Zirconia Surface Treated by Er:YAG Laser with Output Power of $1.5 \mathrm{~W}, 150 \mathrm{~mJ}$ (Original Magnification $\times 3000, \times 15000$, and $\times 60000$ ) 

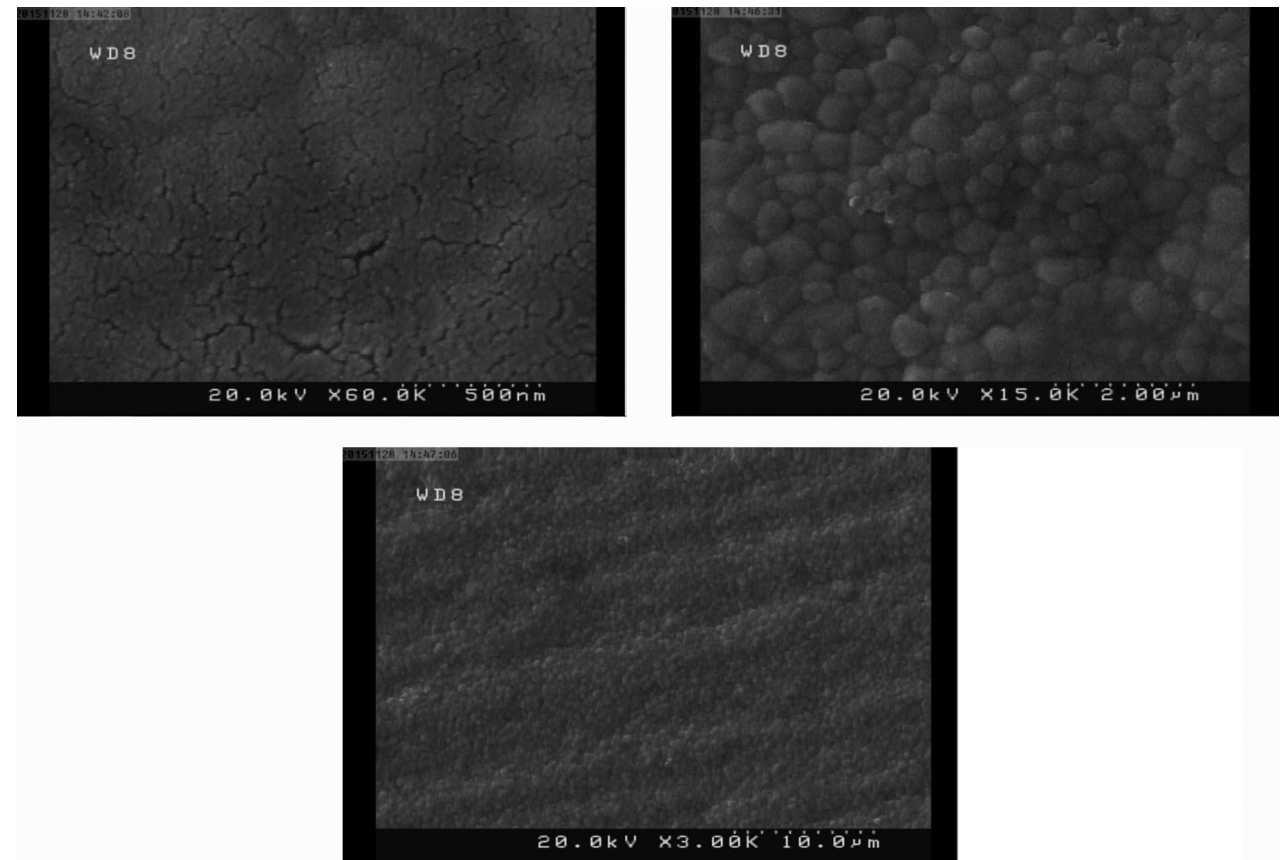

Figure 3. Zirconia Surface Treated by Er:YAG Laser with Output Power of $2.5 \mathrm{~W}, 250 \mathrm{~mJ}$ (Original magnification $\times 3000, \times 15000$, and $\times 60000$ )
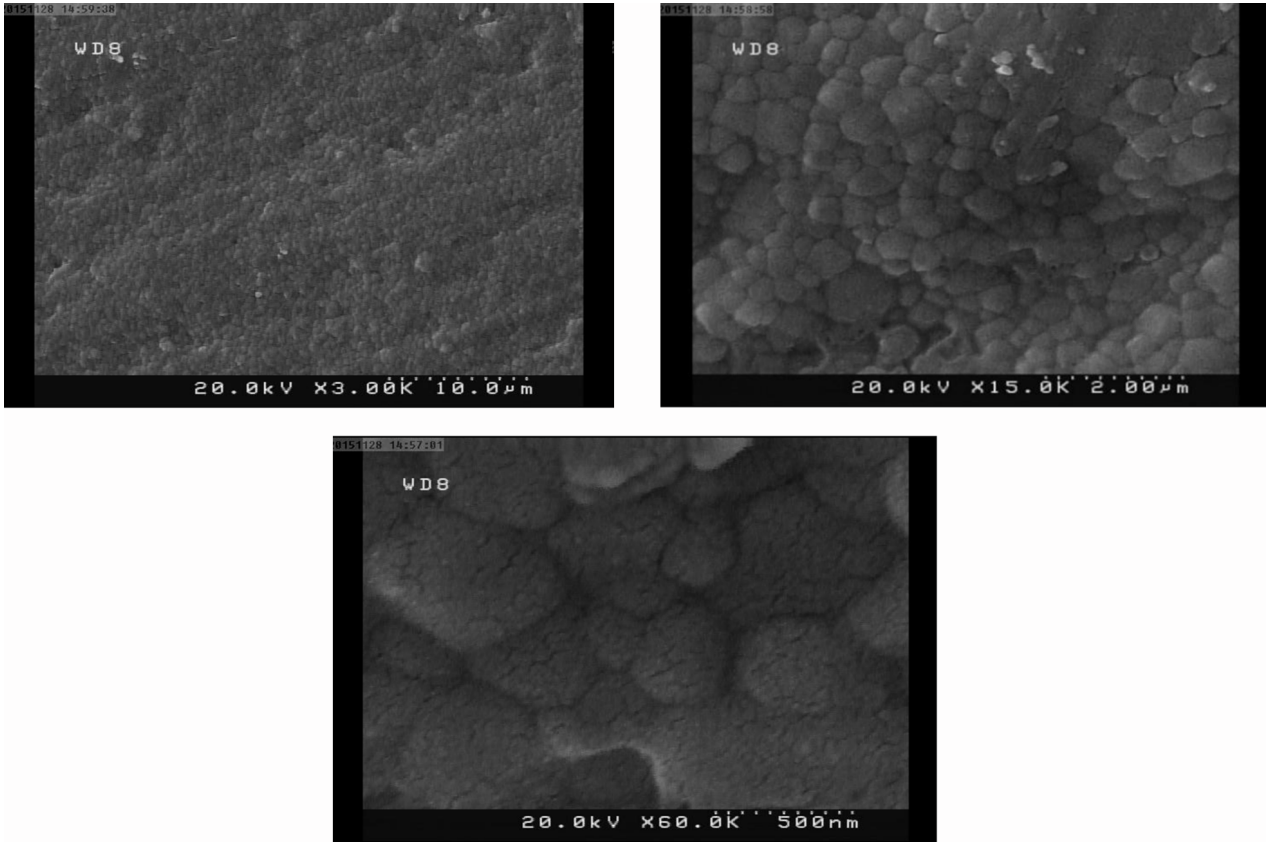

Figure 4. Zirconia surface treated by Er:YAG laser with output power of $3.5 \mathrm{~W}, 350 \mathrm{~mJ}$ (Original magnification $\times 3000, \times 15000$, and $\times 60000$ )

radiation on zirconia $(16,20)$, in the SEM images of laser groups in the present study no microcrack was detected but uneven surface and crystal shape deformation were evident at $\times 15000$ and $\times 60000$ magnifications. Some studies have concluded that high-power laser radiation causes undesirable morphological changes, they have rec- 

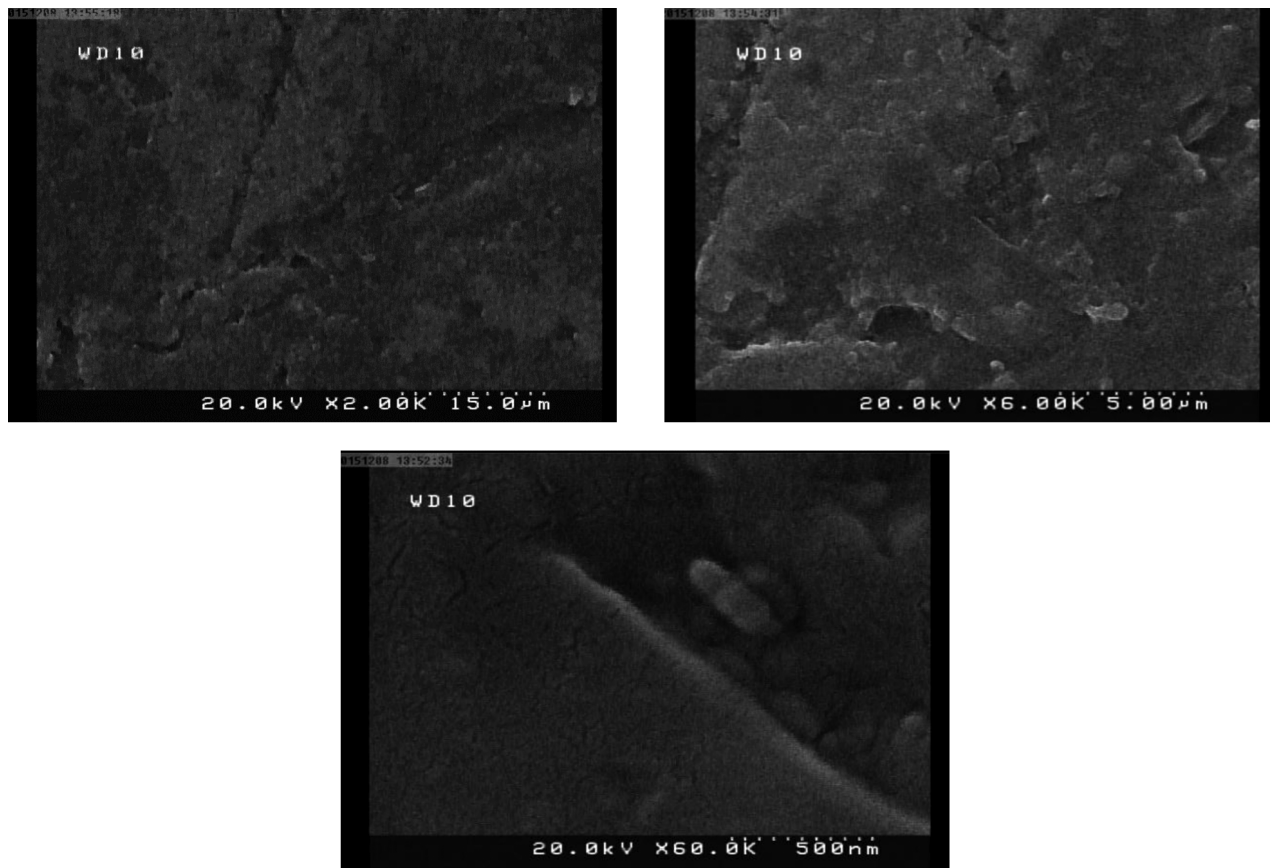

Figure 5. Zirconia Surface Treated by Sandblasting Technique (Original Magnification $\times 2000, \times 6000$, and $\times 60000$ ).

ommended to use $200 \mathrm{~mJ}$ and less powers (20). In our study the change of morphology of surface and crystals were detected at $2.5 \mathrm{~W}(250 \mathrm{~mJ})$ and $3.5 \mathrm{~W}(350 \mathrm{~mJ})$ laser groups. At the $1.5 \mathrm{~W}(150 \mathrm{~mJ})$ laser group no surface change was detected and it was similar to control group. It seems $1.5 \mathrm{~W}$ (150 mJ) Er: YAG laser radiation has no significant effect on surface morphology. This finding is consistent with results of previous studies (20).

\section{Conclusions}

1. By increasing the Er: YAG laser power on zirconia ceramic, the surface roughness increases but not impressive.

2. Application of sandblasting technique on zirconia provides greater surface roughness than Er: YAG laser treatment. This method can create microretentive grooves that probably improve bonding to zirconia.

3. $1.5 \mathrm{~W}(150 \mathrm{~mJ})$ Er: YAG laser radiation has no significant effect on surface morphology of zirconia but $2.5 \mathrm{~W}$ (250 mJ) and $3.5 \mathrm{~W}(350 \mathrm{~mJ})$ outputs change the morphology of zirconia surface and crystals.

\section{Acknowledgments}

Special thanks to Dr. Tabassom Hooshmand, associate professor of dental material department at Tehran Univer- sity of Medical Sciences for her great scientific supports during this research.

\section{References}

1. Madfa AA, Al-Sanabani FA, Al-Qudami NH, Al-Sanabani JS, Amran AG. Use of Zirconia in dentistry: an overview. Open Biomat J. 2014;5(1).

2. Manicone PF, Rossi Iommetti P, Raffaelli L. An overview of zirconia ceramics: basic properties and clinical applications. $J$ Dent. 2007;35(11):819-26. doi: 10.1016/j.jdent.2007.07.008. [PubMed: 17825465].

3. Al-Amleh B, Lyons $\mathrm{K}$, Swain M. Clinical trials in zirconia: a systematic review. J Oral Rehab. 2010 doi: 10.1111/j.1365-2842.2010.02094.x.

4. Denry I, Kelly JR. State of the art of zirconia for dental applications. Dent Mater. 2008;24(3):299-307. doi: 10.1016/j.dental.2007.05.007. [PubMed: 17659331].

5. Garvie RC, Nicholson PS. Structure and Thermomechanical Properties of Partially Stabilized Zirconia in the CaO-ZrO2 System.J American Ceramic Society. 1972;55(3):152-7. doi:10.1111/j.1151-2916.1972.tb11241.x.

6. Zachrisson Y,Zachrisson B, Büyükyilmaz T. Surface preparation for orthodontic bonding to porcelain. Am JOrthod. 1996;109(4):420-30. doi: 10.1016/s0889-5406(96)70124-5.

7. Gillis I, Redlich M. The effect of different porcelain conditioning techniques on shear bond strength of stainless steel brackets. Am J Orthod. 1998;114(4):387-92. doi: 10.1016/s0889-5406(98)70183-0.

8. von Fraunhofer JA, Allen DJ, Orbell GM. Laser etching of enamel for direct bonding. Angle Orthod. 1993;63(1):73-6. doi: 10.1043/00033219(1993)063<0073:LEOEFD>2.0.CO;2. [PubMed: 8507035].

9. Basaran G, Ozer T, Berk N, Hamamci O. Etching enamel for orthodontics with an erbium, chromium:yttrium-scandium-gallium-garnet laser system. Angle Orthod. 2007;77(1):117-23. doi: 10.2319/120605426R.1. [PubMed:17029548]. 
10. van As G. Erbium lasers in dentistry. Dent Clin North Am. 2004;48(4):1017-59. doi: 10.1016/j.cden.2004.06.001. [PubMed: 15464563].

11. Coluzzi DJ. Fundamentals of dental lasers: science and instruments. Dent Clin North Am. 2004;48(4):751-70. doi: 10.1016/j.cden.2004.05.003. [PubMed: 15464551] v.

12. DenBesten PK, White JM, Pelino JEP, Furnish G, Silveira A, Parkins FM. The Safety and Effectiveness of an Er:YAG Laser for Caries Removal and Cavity Preparation in Children. Medical Laser Application. 2001;16(3):215-22. doi:10.1078/1615-1615-00025.

13. Raucci-Neto W, Chinelatti MA, Ito IY, Pecora JD, Palma-Dibb RG. Influence of Er:YAG laser frequency on dentin caries removal capacity. Microsc Res Tech. 2011;74(3):281-6. doi: 10.1002/jemt.20902. [PubMed: 20623778].

14. Yamada Y, Hossain M, Suzuki N, Kinoshita JI, Nakamura Y, Matsumoto K. Removal of carious dentin by Er:YAG laser irradiation with and without carisolv. J Clin Laser Med Surg. 2001;19(3):127-31. doi: 10.1089/10445470152927955. [PubMed:11469304].

15. Kumbuloglu O, Lassila LV, User A, Vallittu PK. Bonding of resin composite luting cements to zirconium oxide by two air-particle abrasion methods. Oper Dent. 2006;31(2):248-55. doi: 10.2341/05-22. [PubMed: 16827029].
16. Caglar I, Yanikoglu N. The Effect of Sandblasting, Er:YAG Laser and Heat Treatment on the Mechanical Properties of Different Zirconia Cores. Photomed Laser Surg. 2016;34(1):17-26. doi: 10.1089/pho.2015.3980. [PubMed: 26653990].

17. Subasi MG, Inan O. Evaluation of the topographical surface changes and roughness of zirconia after different surface treatments. Lasers Med Sci. 2012;27(4):735-42. doi: 10.1007/s10103-011-0965-3. [PubMed: 21786139].

18. Turp V, Sen D, Tuncelli B, Goller G, Ozcan M. Evaluation of air-particle abrasion of Y-TZP with different particles using microstructural analysis. Aust Dent J. 2013;58(2):183-91. doi: 10.1111/adj.12065. [PubMed: 23713638].

19. Karakoca S, Yilmaz H. Influence of surface treatments on surface roughness, phase transformation, and biaxial flexural strength of YTZP ceramics. J Biomed Mater Res B Appl Biomater. 2009;91(2):930-7. doi: 10.1002/jbm.b.31477. [PubMed: 19637376].

20. Cavalcanti AN, Pilecki P, Foxton RM, Watson TF, Oliveira MT, Gianinni $\mathrm{M}$, et al. Evaluation of the surface roughness and morphologic features of Y-TZP ceramics after different surface treatments. Photomed Laser Surg. 2009;27(3):473-9. doi: 10.1089/pho.2008.2293. [PubMed: 19405819]. 